\title{
Detection of epithelial apoptosis in pelvic ileal pouches for ulcerative colitis and familial adenomatous polyposis
}

Raquel F Leal ${ }^{1 *}$, Maria de Lourdes S Ayrizono ${ }^{1}$, Marciane Milanski ${ }^{2}$, João J Fagundes ${ }^{1}$, Juliana C Moraes ${ }^{2}$, Luciana R Meirelles ${ }^{3}$, Lício A Velloso², Cláudio SR Coy ${ }^{1}$

\begin{abstract}
Background: lleal pouch-anal anastomosis (IPAA) is the surgical procedure of choice for patients with refractory ulcerative colitis (UC) and for familial adenomatous polyposis (FAP) with many rectal polyps. Pouchitis is one of the more frequent complications after IPAA in UC patients; however, it is rare in FAP.

Objective: Evaluate pro-apoptotic activity in endoscopically and histological normal mucosa of the ileal pouch in patients with UC and FAP.

Methods: Eighteen patients (nine with UC and nine with FAP) with J pouch after total rectocolectomy were studied. Biopsies were obtained from the mucosa of the pouch and from normal ileum. The specimens were snapfrozen and the expressions of Bax and $\mathrm{BCl}-2$ were determined by immunoblot of protein extracts and by immunohistochemistry analysis. FADD, Caspase-8, APAF-1 and Caspase-9 were evaluated by immunoprecipitation and immunoblot.

Results: Patients with UC had significantly higher protein levels of Bax and APAF-1, Caspase-9 than patients with FAP, but were similar to controls. The expressions of BCl-2 and FADD, Caspase-8 were similar in the groups. Immunohistochemistry for Bax showed less intensity of immunoreactions in FAP than in UC and Controls. BCl-2 immunostaining was similar among the groups.

Conclusion: Patients with FAP present lower levels of pro-apoptotic proteins in all methods applied, even in the absence of clinical and endoscopic pouchitis and dysplasia in the histological analysis. These findings may explain a tendency of up-regulation of apoptosis in UC patients, resulting in higher rates of progression to pouchitis in these patients, which could correlate with mucosal atrophy that occurs in inflamed tissue. However, FAP patients had low pro-apoptotic activity in the mucosa, and it could explain the tendency to low cell turn over and presence of adenomas in this syndrome.
\end{abstract}

\section{Backgroud}

Restorative rectocolectomy with ileal pouch and anal anastomosis (IPAA) has become the surgical procedure of choice for ulcerative colitis (UC) and for familial adenomatous polyposis (FAP), for three decades [1-3]. Despite of its innumerous advantages over other therapeutic procedures, restorative retocolectomy with ileal pouch may evolve with pouchitis, a complication that

\footnotetext{
* Correspondence: raquelleal@mpc.com.br

${ }^{1}$ Coloproctology Unit of the Surgery Department, University of Campinas (UNICAMP), Medical School, São Paulo, Brazil
}

affects up to $50 \%$ of patients with UC, and only $5 \%$ of patients with FAP [4-6].

Although pouchitis is a commonly reported complication, its etiology remains unknown [7-11]. Due to this difference in the incidence of pouchitis, some authors have proposed that the reactivation of UC may have a role in the induction of the local inflammation and in the increased epithelial apoptosis that will, ultimately, lead to the installation of this complication $[12,13]$. This hypothesis is further boosted by the fact that some patients with pouchitis have resurgence of extra-intestinal manifestations of UC in the same way as patients who have active 
UC $[14,15]$, and by data supporting a goal for increased apoptosis that occurs in active UC mucosa [16,17]. The study of intrinsic and extrinsic apoptosis pathways in ileal pouch remains not completely available and there are few studies in the literature that have evaluated this putative role of pouchitis etiology.

Therefore, in order to compare the apoptotic activity in asymptomatic pouches between the highly pouchitisprone UC patients and the pouchitis-protected patients with FAP we employed immunoblotting, immunoprecipitation assays and histological analysis to determine the expression of pro-apoptotic and anti-apoptotic proteins, and detection of apoptosis by Annexin V fluorescence microscopy in ileal pouch biopsies.

\section{Methods}

Mucosal biopsies were taken from nine patients with non-inflamed IPAA after rectocolectomy for UC [median age 48.7 (range, 31-63) years; male 44.4\%; female $55.6 \%]$, and nine patients with non-inflamed IPAA after rectocolectomy for FAP [median age 33.8 (range, 21-59) years; male $44.4 \%$; female $55.6 \%$ ]. The follow-up after the operation was 73.1 (24-168) months. The reservoir design was of the "J" type in all patients, and the right colon vascular arcade was preserved as a supplementary blood supply to the terminal ileum [18]. Mucosectomy was performed, with hand-sewn ileo-anal anastomosis. The patients had had their ileostomy closed for more than one year, at the time of the study. The absence of pouchitis was defined clinically, histology and endoscopically, according to the PDAI [19]. The control group was composed of nine individuals with normal colonoscopy examination, with a median age of 40.9 (range, 26 - 58) years and $55.6 \%$ were female. Six biopsies of each patient were obtained from terminal ileum (control) and from ileal pouch (UC and FAP).

The study was performed in accordance with the Declaration of Helsinki and was approved by the local ethical committee. All biopsies were taken after informed consent from the patients. The study was carried out at the State University of Campinas, Coloproctology Unit, and at the Cell Signaling Laboratory of the Department of Internal Medicine.

\section{- Immunoblotting - Gel electrophoresis}

Mucosal biopsies from the pouches and from normal ileum were snap-frozen in liquid nitrogen and stored at $-80^{\circ} \mathrm{C}$ until use. For total protein extract preparation, the fragments were homogenized in solubilization buffer at $4{ }^{\circ} \mathrm{C}[1 \%$ Triton $\mathrm{X}-100,100 \mathrm{mM}$ Tris- $\mathrm{HCl}(\mathrm{pH} 7.4)$, $100 \mathrm{mM}$ sodium pyrophosphate, $100 \mathrm{mM}$ sodium fluoride, $10 \mathrm{mM}$ EDTA, $10 \mathrm{mM}$ sodium orthovanadate, 2.0 $\mathrm{mM}$ phenylmethylsulfonyl fluoride (PMSF), and $0.1 \mathrm{mg}$ aprotinin/ml] with a Polytron PTA $20 \mathrm{~S}$ generator (model PT 10/35; Brinkmann Instruments, Westbury, $\mathrm{NY}$ ) operated at maximum speed for $30 \mathrm{sec}$. Insoluble material was removed by centrifugation $(20 \mathrm{~min}$ at 9000 $\times g$ at $4^{\circ} \mathrm{C}$ ). The protein concentrations of the supernatants were determined by the Bradford dye binding method [20]. Aliquots of the resulting supernatants containing $100 \mu \mathrm{g}$ total proteins were separated by SDSPAGE, transferred to nitrocellulose membranes and blotted with anti-Bax, anti-Bcl-2 antibodies [21,22]. In immunoprecipitation experiments, samples containing $1.0 \mathrm{mg}$ protein were incubated overnight with antibodies against FADD and APAF-1. The immunocomplexes were recovered with Protein A Sepharose, separated by SDS-PAGE, transferred to nitrocellulose membranes, and blotted with anti-Caspase- 8 to FADD (extrinsic pathway apoptosis), and anti-Caspase-9 to APAF-1 antibodies (intrinsic pathway apoptosis) [21].

Reagents for SDS-PAGE, immunoblotting and immunoprecipitation were from Bio-Rad Laboratories (Richmond, CA). Phenylmethylsulfonyl fluoride, aprotinin, Triton X-100, Tween 20, glycerol were from Sigma (St. Louis, MO). Protein A-Sepharose $6 \mathrm{MB}$ was from Pharmacia (Uppsala, Sweden), and nitrocellulose paper (BA85, $0.2 \mu \mathrm{m}$ ) was from Amersham (Aylesbury, UK). The anti-Bax (sc-493, rabbit polyclonal), anti-Bcl-2 (sc492, rabbit polyclonal), anti-FADD (sc-5559, rabbit polyclonal), anti-Caspase-8 (sc-7890, rabbit polyclonal), antiAPAF-1 (sc 26685, goat polyclonal) and anti-Caspase-9 (sc-7885, rabbit polyclonal) antibodies were purchased from Santa Cruz Biotechnology, Inc. (Santa Cruz, CA). The signal was detected by chemiluminescent reaction (SuperSignal ${ }^{\ominus}$ West Pico Chemiluminescent Substrate from Pierce Biothecnology, Inc. Rockford).

All numerical results are expressed as the mean \pm SEM of the indicated number of experiments. The results of blots are presented as direct comparisons of bands in autoradiographs and quantified by densitometry using the Gel-Pro Analyzer 3.1 software (ExonIntron Inc., Farrell, MD). Data were analyzed by repeat-measure ANOVA (one-way or two-way ANOVA) followed by analysis of significance (TukeyKramer Multiple Comparisons test), comparing UC, FAP, and control groups. The level of significance was set at $\mathrm{p}<0.05$.

\section{- Bax and Bcl-2 Immunohistochemistry}

For immunostaining procedures, endogenous peroxidase was blocked with $3 \%$ hydrogen peroxide/10 mM PBS $\mathrm{pH} 6.0$ for $15 \mathrm{~min}$. Afterwards, the sections were microwaved in 3\% milk buffer for $30 \mathrm{~min}$ and incubated overnight with primary antibody either to Bax or Bcl-2 (DAKO A/S Denmark; A3533, rabbit polyclonal and M0887, mouse polyclonal) applied in 1:500 and 1:150 dilution respectively at $20^{\circ} \mathrm{C}$. The sections were 
incubated with post primary block and polymer secondary antibodies (Novocastra ${ }^{\mathrm{mm}}$ Laboratories Ltd; Novolink RE 7260-K) for $1 \mathrm{~h}$, and processed for DAB reaction, $0.5 \mathrm{mg} / \mathrm{ml}$ (Sigma, USA, St Louis). Any cell type showing cytoplasmic staining was considered positive for qualitative analysis [23,24].

\section{Results}

Patients with UC had significantly higher levels of Bax, APAF-1 and Caspase-9 than FAP ( $p<0.05)$, but were similar to controls $(\mathrm{p}>0.05)$. The comparison of local levels of Bcl-2 in pouches from UC, FAP patients and controls revealed that they were similar among the groups ( $\mathrm{p}>0.05)$.

The expression of FADD and Caspase- 8 was similar among the groups $(\mathrm{p}<0.05)$, however there was a tendency of high levels in UC patients when compared to other groups $(\mathrm{p}=0.08)$.

The determination of proteins expressions are shown in Figure 1.

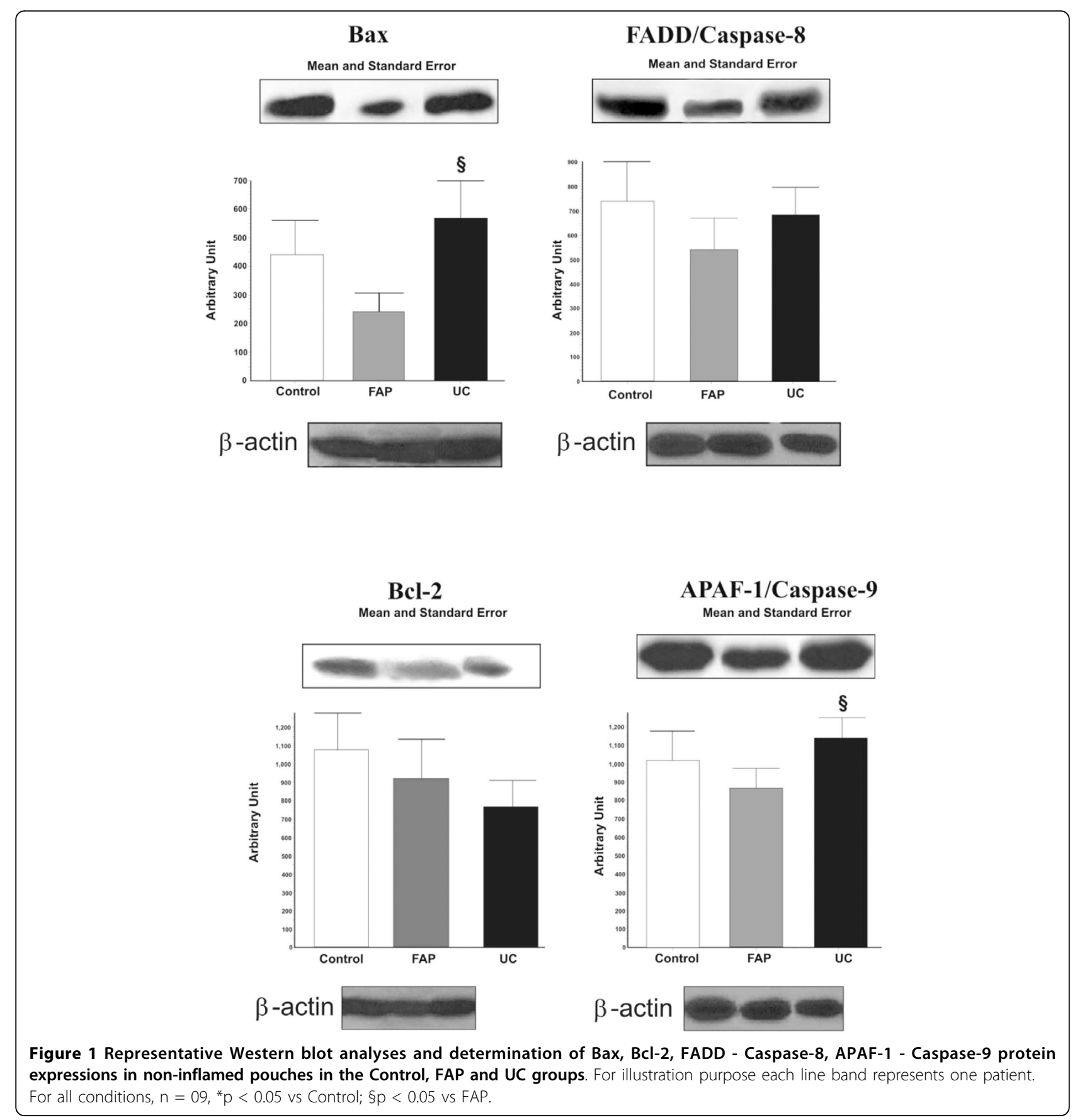


With regard to immunohistochemistry, it showed that immunoreactivity for Bax and $\mathrm{Bcl}-2$ were detected in all groups. Bcl-2 immunostaining pattern was similar among the groups (Figure 2).

\section{Discussion}

Pouchitis is a common complication of total rectocolectomy with ileal pouch-anal anastomosis [25]. The etiology of primary pouchitis remains uncertain and several theories have been suggested like recurrence of UC in ileal pouch. This fact precluded the development of appropriate prophylaxis and treatment.

The fecal stream and stasis play an important part in the pathogenesis of immunological reactions in the ileal pouch, but don't explain the difference in incidence of pouchitis in UC and FAP patients. There were immunological changes in the pouch for at least one year after ileostomy closure in adaptation way after this surgery [26]. Our patients in this study had more than $1 \mathrm{yr}$ of follow-up after ileostomy closure, in order to evaluate

\section{BAX}

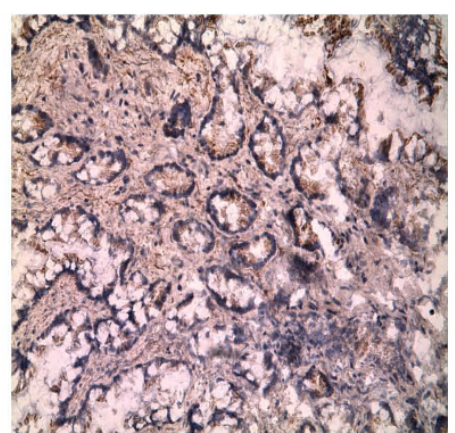

Control

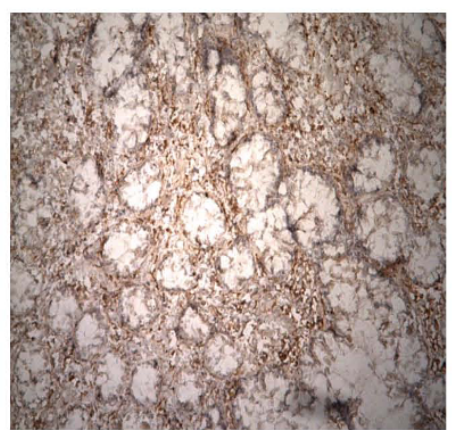

FAP

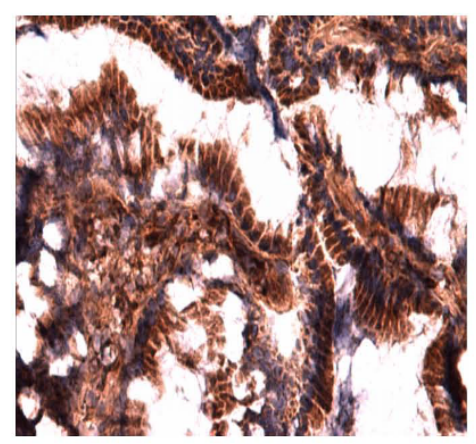

UC

\section{$\mathrm{Bcl}-2$}

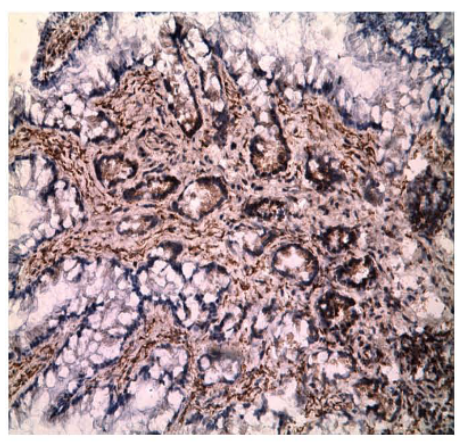

Control

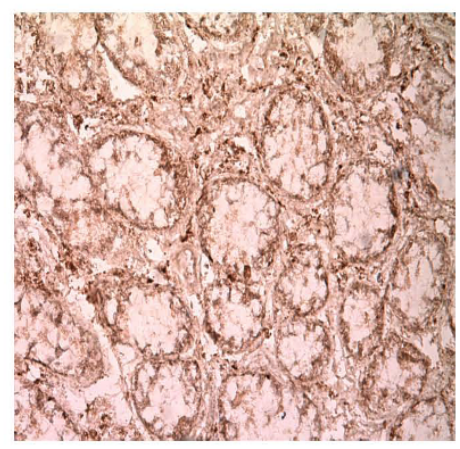

FAP

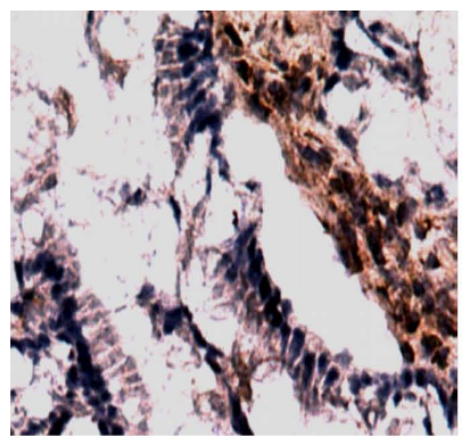

UC

Figure 2 Immunohistochemistry of ileal pouch sections from UC, FAP and control group immunoreacted for Bax and Bcl-2. Immunostainig for Bax was intense in UC group. BCl-2 positive cell among the groups was similar. (200X) 
apoptosis activity that could lead to pouchitis after this transitional period.

Several cytokines have been reported in ileal pouches, showing that pro-inflammatory cytokines like TNF- $\alpha$, IL-1 $\beta$, IL-6, IL-8, IFN- $\gamma$ are elevated in UC patients, but poorly studied in FAP $[4,27-30]$.

The inflammatory and apoptosis pathways are linked and some pro-inflammatory cytokines, such TNF- $\alpha$, are evolved in regulation of cell apoptosis. The elevated expression of Fas-Fas-L (CD95-CD95L), a pro-apoptotic member of the TNF-superfamily, has been reported in ileal pouches of patients with UC and a history of pouchitis, but it wasn't compared to FAP patients. It has been related to the role of increased epithelial turn over in the etiology of pouchitis [12]. Indeed, another study reported higher expression of Bad, a potent pro-apoptotic protein of Bcl-2 family, in ileal pouch of UC patients when compared to FAP [13].

This study, we evaluated the expression of pro-apoptotic and anti-apoptotic proteins of Bcl-2 [31,32] and Caspases [33,34] families to evaluate intrinsic and extrinsic pathways of apoptosis in normal ileal pouches. Even in such optimal clinical, endoscopic and histological conditions, the local levels of pro-apoptotics proteins were high in UC patients. Bax, APAF-1 and Caspase-9 expressions were very higher, and FADD, Caspase- 8 expressions had a discrete tendency to be more intense in UC patients when compared to FAP. This fact is extremely interesting showing that there is an up-regulating of apoptosis in UC, which could lead or correlate with inflammation tendency in these pouches. It could be due to the fact that both inflammatory and apoptosis pathways are related.

Furthermore, the major pathway of apoptosis in these cases were intrinsic mitochondrial pathway characterized by APAF-1 and Caspase- 9 expressions, and it is by according to higher levels of Bad, a member of Bcl-2 family that stays in the mitochondrial membrane, verified in ileal pouches of UC patients in another study [13]. With regard to similar Bcl-2 expression in the different groups, it could mean that all patients were asymptomatic with normal endoscopic and histological features, so there is a balance between pro and anti-apoptotic activities. The increased apoptosis plays an important role in the pathogenesis of pouchitis and probably not a defective of down-regulation promoted by anti-apoptotic proteins. These results were emphasized by results of $\mathrm{Bax}$ and $\mathrm{Bcl}-2$ immunohistochemistry.

In the other side, FAP had less expression of proapoptotic proteins, thus minor potential cell turn over and it might have a tight connection with primary disease in these patients. Some authors have been reported adenomas in ileal pouch of FAP, more commonly than in UC patients, who have more inflammatory polyps [35-38]. It could be due to low cell turn over that occurs in FAP ileal pouches.

The importance in knowing of the pathways of cell apoptosis in ileal pouch can lead us to understand more about molecular biology involved in pouchitis, and in the primary diseases, FAP and UC.

\section{Conclusions}

In summary, the present study shows that, even under non-inflammatory conditions, patients with UC present higher levels of pro-apoptotic protein in the normal mucosa of pouches. The higher pro-inflammatory cytokines expression in UC, when compared with FAP, verified in the literature, suggests that primary defects of macrophage-lymphocyte regulation, which may coincide with defective regulation of apoptosis, showed in this study, playing an important role in the development of local inflammation in this group of patients. Moreover, we showed a defective regulation of apoptosis in the mucosa of FAP pouches.

\section{Acknowledgements}

We thank ALN Domingues (Inflammatory Bowel Disease Ambulatory Coloproctology Unit), A Coope, for technical assistance. These studies were supported by the Fundação de Amparo à Pesquisa do Estado de São Paulo and Fundo de Apoio ao Ensino, à Pesquisa e à Extensão.

\section{Author details}

${ }^{1}$ Coloproctology Unit of the Surgery Department, University of Campinas (UNICAMP), Medical School, São Paulo, Brazil. ${ }^{2}$ Internal Medicine Department, Cellular Signalization Laboratory, University of Campinas (UNICAMP), Medical School, São Paulo, Brazil. ${ }^{3}$ Department of Pathology, University of Campinas, Medical School, Sao Paulo, Brazil.

\section{Authors' contributions}

RFL carried out the molecular studies, drafted the manuscript and statistical analysis. MLSA participated in colonoscopy examinations to obtain mucosal biopsies. MM carried out the immunoblotting assays. JJF participated in the design of the study. JCM carried out the Anexin V analysis. LRM carried out the immunohistochemistry procedures. LAV participated in its design and performed the statistical analysis. CSRC participated in its design and coordination, and helped to draft the manuscript. All authors read and approved the final manuscript.

\section{Competing interests}

The authors declare that they have no competing interests.

Received: 11 June 2009

Accepted: 29 January 2010 Published: 29 January 2010

\section{References}

1. Parks AG, Nicholls RJ: Proctocolectomy without ileostomy for ulcerative colitis. Br Med J 1978, 2:85-87.

2. M'Koma AE: Serum biochemical evaluation of patients with functional pouches tem to 20 years after restorative proctocolectomy. Int J Colorectal Dis 2006, 26:1-10.

3. McGuire BB, Brannigan AE, O'Connell PR: lleal pouch-anal anastomosis. $\mathrm{Br} J$ Surg 2006, 94:812-823.

4. Kiehne K, Brunke G, Wegner F, Banasiewicz T, Folsch UR, Herzig KH: Defensin expression in chronic pouchitis in patients with ulcerative colitis or familial adenomatous polyposis coli. World I Gastroenterol 2006, 21:12(7):1056-1062. 
5. Heuschen UA, Allemeyer EH, Hinz U, Autschbach F, Uehlein T, Herfarth C, Heuschen G: Diagnosing pouchitis: comparative validation of two scoring system in routine follow-up. Dis Colon Rectum 2002, 45(6):776-786.

6. Shen B, Fazio W, Renzi FH, Brzezinski A, Bennett AE, Lopez R, Hammel JP, Achkar JP, Bevins CL, Lavery IC, Strong SA, Delaney CP, Liu W, Bambrick ML, Sherman KK, Lashner BA: Risk factors for disease of ileal pouch-anal anastomosis after restorative proctocolectomy for ulcerative colitis. Clin Gastroenterol Hepatol 2006, 4(1):81-89.

7. Armstrong DN, Sillin LF, Chung R: Reduction in tissue blood flow in Jshaped pelvic ileal reservoirs. Dis Colon Rectum 1995, 38:526-529.

8. Laake KO, Bjorneklett A, Aamodt G, Aabakken L, Jacobsen M, Bakka A, Vatn $\mathrm{MH}$ : Outcome of four weeks's intervention with probiotics on symptoms and endoscopic appearance after surgical reconstruction with a J-configurated ileal-pouch-anal-anastomosis in ulcerative colitis. Scand J Gastroenterol 2005, 40:43-51.

9. Ohge H, Furne JK, Springfield J, Rothenberger DA, Madoff RD, Levitt MD Association between fecal hydrogen sulfide production and pouchitis. Dis Colon Rectum 2005, 48:469-475.

10. Kuehbacher T, Ott SJ, Helwig U, Mimura T, Rizzello F, Kleessen B, Gionchetti P, Blaut M, Campieri M, Folsch UR, Kamm MA, Schreiber S: Bacterial and fungal microbiota in relation to probiotic therapy in pouchitis. Gut 2006, 55(6):833-841.

11. Nicholls RJ, Banerjee AK: Pouchitis: risk factores, etiology, and treatment. World J Surg 1998, 22:347-356.

12. Coffey JC, Bennett MW, Wang JH, O'Connell J, Neary P, Shanahan F, Redmond HP, Kirwan WO: Upregulation of Fas-Fas-L (CD95/CD95L)mediated ephitelial apoptosis - a putative role in pouchitis?. J Surg Res 2001, 98:27-32.

13. Leal RF, Coy CSR, Ayrizono MLS, Fagundes JJ, Milanski M, Saad MJ, Velloso LA, Góes JRN: Differential expression of pro-inflammatory cytokines and a pro-apoptotic protein in pelvic ileal pouches for ulcerative colitis and familial adenomatous polyposis. Tech Coloproctol 2008, 12:33-38.

14. Lohmuller JL, Pemberton JH, Dozois RR, Ilstrup D, Heerden JV: Pouchitis and extraintestinal manifestations of inflammatory bowel disease after ileal pouch-anal anastomosis. Ann Surg 1990, 211(5):622-629.

15. Hata K, Watanabe T, Shinozaki M, Nagawa H: Patients with extraintestinal manifestations have a higher risk of developing pouchitis in ulcerative colitis: multivariate analysis. Scand J Gastroenterol 2003, 38:1055-1058.

16. Ueyama H, Kiyohara T, Sawada N, Isozaki K, Kitamura S, Kondo S, Miyagawa J, Kanayama S, Shinomura Y, Ishikawa H, Ohtani T, Nezu R, Nagata S, Matsuzawa Y: High Fas ligand expression on lymphocytes in lesions of ulcerative colitis. Gut 1998, 43:48-55.

17. Bennett MW, O'Connell J, O'Sullivan GC, Collins JK, Shanahan F: Altered expression of Fas ligand by colonic epithelium in Crohn's disease and ulcerative colitis [abstract]. Gastroenterology 1998, 114:A929.

18. Góes JR, Coy CS, Amaral CA, Fagundes JJ, Medeiros R: Superior mesenteric artery syndrome as a complication of ileal pouch-anal anastomosis. Dis Colon Rectum 1995, 38:543-4.

19. Sandborn WJ, Tremaine WJ, Batts KP, Pemberton JH, Phillips SF: Pouchitis after ileal pouch-anal anastomosis: a Pouchitis disease activity index. Mayo Clin Proc 1994, 69:409-415.

20. Bradford MM: A rapid and sensitive method for the quantitation of microgram quantities of protein utilizing the principle of protein-dye binding. Anal Biochem 1976, 72:248-254.

21. Velloso LA, Folli F, Sun XJ, White MF, Saad MJA, Kahn CR: Cross-talk between the insulin and angiotensin signaling systems. Proc Natl Acad Sci USA 1996, 93:12490-12495.

22. Araújo EP, De Souza CT, Gasparetti AL, Ueno M, Boschero AC, Saad MJA Velloso LA: Short-term in vivo inhibition of insulin receptor substrate-1 expression leads to insulin resistence, hyperinsulinemia, and increased adiposity. Endocrinology 2005, 146:1428-1437.

23. Hsu SM, Raine L, Fanger H: Use of Avidin-Biotin-Peroxidase Complex $(A B C)$ in immunoperoxidase techniques: a comparison between $A B C$ and unlabeled antibody (PAP) procedures. J Histochem Cytochem 1981, 29:577-580.

24. Huerta S, Goulet EJ, Huerta-Yepez S, Livingston EH: Screening and Detection of Apoptosis. J Surg Res 2007, 139:143-156.

25. Kuhbacher T, Schreiber S, Runkel N: Pouchitis: pathophysiology and treatment. Int J Colorectal Dis 1998, 13:196-207.
26. Yamamoto $T$, Umegae $S$, Kitagawa $T$, Matsumoto $K$ : The impact of the fecal stream and stasis on immunologic reactions in ileal pouch after restorative proctocolectomy for ulcerative colitis: a prospective, pilot study. Am J Gastroenterol 2005, 100:2248-2253.

27. Gionchetti P, Campieri M, Belluzzi A, Bertinelli E, Ferretti M, Brignola C, Poggioli G, Miglioli M, Barbara L: Mucosal concentrations of interleukin-1 beta, interleukin-6, interleukin-8, and tumor necrosis factor-alpha in pelvic ileal pouches. Dig Dis Sci 1994, 39:1525-1531.

28. Patel RT, Bain I, Youngs D, Keighley MRB: Cytokine production in pouchitis is similar to that in ulcerative colitis. Dis Colon Rectum 1995, 38:831-837.

29. Bulois P, Tremaine WJ, Maunoury V, Gambiez L, Hafraoui S, Leteurtre E, Cortot A, Sandborn WJ, Colombel JF, Desreumaux P: Pouchitis is associated with mucosal imbalance between interleukin-8 and interleukin-10. Inflamm Bowel Dis 2000, 6:157-167.

30. Lammers KM, Vergopoulos A, Babel N, Gionchetti P, Rizzello F, Morselli C, Caramelli E, Fiorentino M, d'Errico A, Volk HD, Campieri M: Probiotic therapy in the prevention of pouchitis onset: decreased Interleukin-1 $\beta$, Interleukin-8 and Interferon- $\gamma$ gene expression. Inflamm Bowel Dis 2005, 11(5):447-454.

31. Kuwana T, Newmeyer DD: BCl-2 family proteins and the role of mitochondria in apoptosis. Curr Opin Cell Biol 2003, 15:691-699.

32. Festjens N, Van Gurp M, Van Loo G, Saelens X, Vandenabeele P: Bcl-2 family members as sentinels of cellular integrity and role of mitochondrial intermembrane space proteins in apoptotic cell death. Acta Haematol 2004, 111:7-27.

33. Vermeulen K, Van Bockstaele DR, Bernemann ZN: Apoptosis: mechanisms and relevance in cancer. Ann Hematol 2005, 84:627-639.

34. Widmann C, Gibson S, Johnson GL: Caspase-dependent cleavage of signaling proteins during apoptosis. A turn-off mechanism for antiapoptotic signals. J Biol Chem 1998, 273:7141-7147.

35. Schaus BJ, Fazio WW, Remzi FH, Bennett AE, Lashner BA, Shen B: Clinical features of ileal pouch polyps in patients with underlying ulcerative colitis. Dis Colon Rectum 2007, 50:832-838.

36. Nilubol N, Scherl E, Bub DS, Gorfine SR, Marion J, Harris MT, Kornbluth A Lichtiger S, Rubin P, George J, Chapman M, Harpaz N, Present D, Bauer JJ: Mucosal dysplasia in ileal pelvic pouches after restorative proctocolectomy. Dis Colon Rectum 2007, 50:825-831.

37. Kartheuser A, Stangherlin P, Brandt D, Remue C, Sempoux C: Restorative proctocolectomy and ileal pouch-anal anastomosis for familial adenomatous polyposis revisited. Fam Cancer 2006, 5:241-260.

38. Parc YR, Olschwang S, Desaint B, Schmitt G, Parc RG, Tiret E: Familial adenomatous: prevalence of adenomas in the ileal pouch after restorative proctocolectomy. Ann Surg 2001, 233:360-4.

doi:10.1186/1479-5876-8-11

Cite this article as: Leal et al.: Detection of epithelial apoptosis in pelvic ileal pouches for ulcerative colitis and familial adenomatous polyposis. Journal of Translational Medicine 2010 8:11.

\section{Submit your next manuscript to BioMed Central and take full advantage of:}

- Convenient online submission

- Thorough peer review

- No space constraints or color figure charges

- Immediate publication on acceptance

- Inclusion in PubMed, CAS, Scopus and Google Scholar

- Research which is freely available for redistribution

Submit your manuscript at www.biomedcentral.com/submit
Biomed Central 